\title{
Temperature Effect on the Electrooxidation of Gamma Hydroxybutyric Acid (GHB) on Platinum Catalyst through Cyclic Voltammetry, Chronoamperometry, Impedance Spectroscopy and SERS Spectroelectrochemistry
}

\author{
R. Jiménez-Pérez ${ }^{2}$, J.M. Sevilla ${ }^{2}$, T. Pineda ${ }^{2}$, M. Blázquez ${ }^{2}, J$. Gonzalez-Rodriguez ${ }^{1, *}$ \\ ${ }^{1}$ School of Chemistry, College of Science, University of Lincoln, Brayford Pool, Lincoln, LN67TS, \\ UK. Telephone: +441522886878 . \\ ${ }^{2}$ Departamento de Química Física y Termodinámica Aplicada, Universidad de Córdoba, Campus de \\ Rabanales, Ed. Marie Curie, E-14071 Córdoba, España \\ *E-mail: jgonzalezrodriguez@ lincoln.ac.uk
}

doi: $10.20964 / 2016.12 .77$

Received: 20 September 2016 / Accepted: 13 October 2016 / Published: 10 November 2016

\begin{abstract}
A study of the electro-oxidation of gamma hydroxybutyric acid (GHB) on platinum electrode in acidic media has been investigated by cyclic voltammetry, chronoamperometry and electrochemical impedance spectroscopy in the temperature range between 5 and $30^{\circ} \mathrm{C}$. The variation of the $\mathrm{j}$-E curves allows the determination of activation energy in a wide interval of potentials where three characteristic oxidation peaks appear. The $\mathrm{j}$ - $\mathrm{t}$ curves were registered at the more positive potentials corresponding with the A and B peaks. Stationary current intensity measurements allowed the determination of the activation energy in pure kinetic region conditions. Electrochemical impedance spectroscopy made also possible the study of the electrochemical behavior in the same potential region. Temperature dependence of the charge-transfer resistance (Rct) and the rate constant associated with the surface coverage by an adsorbed intermediate $\left(\tau^{-1}=\mathrm{Ro} / \mathrm{L}\right)$ during the GHB electro-oxidation process were evaluated and discussed. In all cases, the values of activation energy, below $30 \mathrm{~kJ} / \mathrm{mol}$, suggest that a complex mechanism takes place for the GHB electro-oxidation free of strong interactions with the platinum surface. In situ Surface Enhanced Raman Scattering (SERS) spectroelectrochemistry spectra corresponding to coadsorbed species, including intermediates of reaction, have been analyzed at several potentials.
\end{abstract}

Keywords: GHB, impedance spectroscopy, activation energy, platinum-catalysed, Surface-Enhanced Raman Spectroscopy (SERS) spectro-electrochemistry.

\section{$\underline{\text { FULL TEXT }}$}


(C) 2016 The Authors. Published by ESG (www.electrochemsci.org). This article is an open access article distributed under the terms and conditions of the Creative Commons Attribution license (http://creativecommons.org/licenses/by/4.0/). 